Check for updates

Cite this: Mater. Adv., 2021, 2, 7881

Received 21st July 2021 Accepted 3rd October 2021

DOI: $10.1039 / \mathrm{d} 1 \mathrm{ma} 00633 a$

rsc.li/materials-advances

\section{Temperature-dependent morphology-electron mobility correlations of naphthalene diimide- indacenodithiophene copolymers prepared via direct arylation polymerization $\dagger$}

\author{
Desiree Adamczak, ${ }^{a}$ Bianca Passarella, ${ }^{\text {bc }}$ Hartmut Komber, (D) d David Becker-Koch, ${ }^{e}$ \\ Oleksandr Dolynchuk, (D) Simon B. Schmidt, (D) ${ }^{\text {a }}$ Yana Vaynzof, (D) e \\ Mario Caironi (iD ${ }^{b}$ and Michael Sommer (D) *a
}

\begin{abstract}
A series of defect-free $n$-type copolymers poly(naphthalene diimide-alt-indacenodithiophene) P(NDIIDT) comprising alternating naphthalene diimide (NDI) and indacenodithiophene (IDT) units is prepared using atom-economic direct arylation polycondensation (DAP). Copolymers with varying molecular weights up to $M_{n, S E C}=113 \mathrm{~kg} \mathrm{~mol}^{-1}$ are obtained in high yield and used to investigate the optical, thermal and electrical properties as a function of chain length. Two weak endotherms are seen in differential scanning calorimetry experiments at $68^{\circ} \mathrm{C}$ and $180-220^{\circ} \mathrm{C}$, depending on molecular weight, which are ascribed to side chain $\left(T_{m, 1}\right)$ and main chain $\left(T_{m, 2}\right)$ melting, respectively. Thin-film morphologies are weakly crystalline for annealing temperatures below $T_{m, 2}$, with organic field-effect (OFET) mobilities being on the order of $10^{-3} \mathrm{~cm}^{2} \mathrm{~V}^{-1} \mathrm{~s}^{-1}$. Under these conditions very low Urbach energies $\left(E_{\mathrm{U}}\right)$ between 28 and $30 \mathrm{meV}$ are found. However, thermal annealing above $T_{\mathrm{m}, 2}$ results in amorphous morphologies with hypsochromically shifted optical spectra, strongly increased $E_{U}$ and complete loss of mobility. In comparison to the well-investigated bithiophene analogue PNDIT2, P(NDI-IDT) thin films are significantly less crystalline, and solutions lack the typical features of aggregation. This is ascribed to the additional bulky hexylphenyl side chains of P(NDI-IDT) that hamper main chain ordering and aggregate formation and thus, interchain charge hopping. With intrachain transport being limited as well, fieldeffect electron mobilities are limited to $\sim 10^{-3} \mathrm{~cm}^{2} V^{-1} \mathrm{~s}^{-1}$ and mostly independent of chain length. These results demonstrate the importance of both intra- and interchain transport to electron mobility for NDI main chain copolymers.
\end{abstract}

\section{Introduction}

Conjugated polymers are useful materials for high-performance organic electronic devices ${ }^{1-3}$ such as organic solar cells (OSCs) ${ }^{4,5}$ or organic field-effect transistors (OFETs). ${ }^{4,6}$ Especially donoracceptor copolymers have emerged as modular systems due to versatile tailoring of their structural and electronic properties by suitable selection of donor and acceptor blocks. ${ }^{7-9}$ In the last decade, one focus has been the development of new n-type polymers for OSCs and OFETs. ${ }^{10-14}$ Many of these n-type conjugated polymers are based on naphthalene diimide (NDI), perylene diimide (PDI) or bithiophene imide (BTI). ${ }^{10,15-17} \mathrm{~A}$ prominent and well-known representative is the naphthalene diimide bithiophene copolymer P(NDIT2), which exhibits intriguing optical and electrical properties. ${ }^{16,18,19}$ Thus, it has been widely employed in all-polymer solar cells (all-PSCs) yielding power conversion efficiencies (PCEs) up to $10 \% .^{20-22}$ Moreover, derivatization of $\mathrm{P}(\mathrm{NDIT} 2)$ as lead structure upon variation of 
the NDI monomer, ${ }^{23-25}$ the donor comonomer, ${ }^{15,16,26,27}$ or the side chains ${ }^{28-31}$ has been the subject of many reports. While performance of n-type polymers is rapidly catching up in the area of organic photovoltaics (OPVs), ${ }^{10,32,33}$ progress in other domains such as organic thermoelectrics and energy storage systems may still profit from further development. ${ }^{34,35}$ The replacement of bithiophene with the fused donor indacenodithiophene (IDT) has opened up further possibilities for n-type copolymers. $^{28,36-38}$ IDT building blocks are highly rigid and coplanar and can be easily modified by, for example, side chain variation and backbone extension. ${ }^{39-41}$ Thereby, polymers such as PIDTBT were designed with low degree of energetic disorder leading to superior charge transport properties. ${ }^{39,42-44}$ Copolymerisation of IDT with NDI yields low band gap copolymers with n-type transistor characteristics and typical dual band absorption in the red and blue region of visible light. First fabrications of all-PSC devices in combination with common donor materials such as $\mathrm{J} 51,{ }^{36} \mathrm{PBDB}^{\mathrm{T}}{ }^{38}$ and $\mathrm{PBZ}-\mathrm{C}^{28}{ }^{28}$ has led to PCEs of $>5 \%$. Another possible application are flexible n-channel organic phototransistors (OTPRs) which can be used in skin therapy systems yielding mobilities in the range from $10^{-5}$ to $10^{-4} \mathrm{~cm}^{2} \mathrm{~V}^{-1} \mathrm{~s}^{-1} \cdot{ }^{37}$

Next to the choice of building blocks, control over molecular weight (MW) and defects are prime prerequisites for optimizing performance and achieving reproducibility. Syntheses of copolymers based on NDI and/or IDT mostly employ Stille polycondensation, ${ }^{36-38}$ a technique that comes along with several well-known drawbacks. ${ }^{45-50}$ The use of direct arylation polycondensation (DAP) is not only more atom-economic, costefficient and faster as less reaction steps are involved, ${ }^{4,51,52}$ but also ideally suited for virtually all combinations of $\mathrm{NDIBr}_{2}$ and thiophene-based comonomers. ${ }^{21,26,53-55}$ Thus, DAP has been successfully applied to the synthesis of defect-free NDI-based copolymers. ${ }^{26,53,54}$ However, few reports on IDT-based copolymers made by DAP exist, and little is known about defects. ${ }^{28,56-58}$ Recently, we reported synthesis of well-defined IDT homo- and copolymers via DAP ${ }^{59,60}$ However, in order to optimize the performance of the material it is essential to understand its structure-property relationships. The influence of MW, end groups, processing solvents and post-temperature treatments are important factors that govern morphology and need to be optimized to understand the performance of new materials for organic electronics.

Here we present a detailed study of the synthesis, the characterization and the effect of annealing temperature on the morphology and optoelectronic properties of $\mathrm{P}$ (NDI-IDT) made by DAP. Polycondensation of $n$-hexylphenyl-substituted IDT with $\mathrm{NDIBr}_{2}$ yields defect-free $\mathrm{P}(\mathrm{NDI}-\mathrm{IDT})$ in high yields and varying molecular weights up to $M_{\mathrm{n}, \mathrm{SEC}}=113 \mathrm{~kg} \mathrm{~mol}^{-1}$. The polymers show a broad CT band around $728 \mathrm{~nm}$ with a band gap of $1.5 \mathrm{eV}$. While in solution the CT band is highly affected by MW, thin film absorption is mostly dependent on thermal annealing. For annealing below main chain melting, P(NDIIDT) thin films show weakly crystalline behavior and very low Urbach energies below $30 \mathrm{meV}$. However, field-effect mobilities are at a modest level, on the order of $10^{-3} \mathrm{~cm}^{2} \mathrm{~V}^{-1} \mathrm{~s}^{-1}$. Upon thermal annealing above main chain melting, thin film morphologies become amorphous, resulting in blue-shifted absorption, significantly increased Urbach energies and loss of mobilities. Compared to P(NDIT2), thin films show much weaker crystallinity and lower field-effect mobilities, mainly owing to the additional bulky hexylphenyl side chains in P(NDIIDT) that hinder aggregation and interchain charge transport.

\section{Results and discussion}

\section{Synthesis and characterization}

Copolymerization of $n$-hexylphenyl-substituted indacenodithiophene $\left(\mathrm{Ph}_{6}\right.$-IDT) and 2,6-dibromonaphthalene diimide with 2-octyldodecyl side chains $\left(\mathrm{NDIBr}_{2}\right)$ via DAP yielded $\mathrm{P}(\mathrm{NDI}-\mathrm{IDT})$ copolymers with high molar masses $M_{\mathrm{n}, \mathrm{SEC}}$ up to $113 \mathrm{~kg} \mathrm{~mol}^{-1}$ (Scheme 1 and Table 1). These rather high values were achieved as a result of appropriately chosen reaction conditions as well as high solubility, which in turn is caused by side chains being present at both comonomers. Control over molecular weight could be achieved by regulation of reaction temperature and monomer concentration. A reduction of either one of these parameters led to an increase in molar mass (entries P4-P6). We assume that lowering monomer concentration allow longer chains to build up before gelation of the reaction mixture sets in. A reduction of the reaction temperature may suppress degradation of NDI-Br chain ends, similar to previously reported IDT copolymers with benzodiathiazole. ${ }^{60}$ Interestingly, all polymerizations stopped following gelation of the mixture after a few hours, indicating a rapid build-up of MW. An exception is entry P1, where the low concentration and

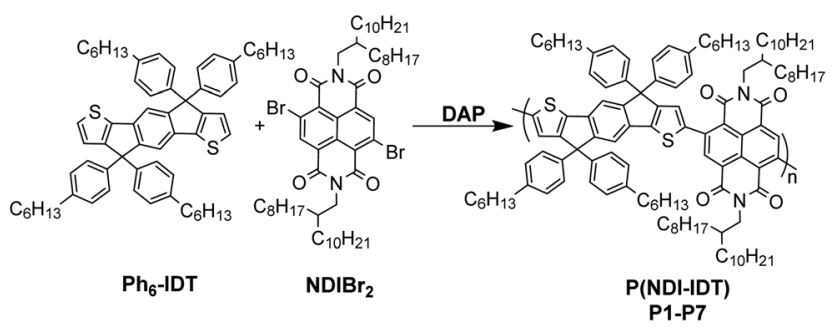

Scheme 1 Synthesis of P(NDI-IDT) via direct arylation polycondensation.

Table 1 Reaction conditions of P(NDI-IDT) ${ }^{a}$

\begin{tabular}{|c|c|c|c|c|c|c|c|}
\hline Entry & Solvent & $\begin{array}{l}{[\mathrm{IDT}]} \\
\text { (M) }\end{array}$ & $\begin{array}{l}T \\
\left({ }^{\circ} \mathrm{C}\right)\end{array}$ & $\begin{array}{l}\text { Cat/P-ligand } \\
(\mathrm{mol} \%)\end{array}$ & $\begin{array}{l}M_{\mathrm{n}} / M_{\mathrm{w}}{ }^{b} \\
\left(\mathrm{~kg} \mathrm{~mol}^{-1}\right)\end{array}$ & $\oplus^{b}$ & $\begin{array}{l}\text { Yield }^{c} \\
(\%)\end{array}$ \\
\hline P1 & Mesitylene & 0.1 & 100 & $5 / 20$ & $18 / 25$ & 1.4 & 60 \\
\hline P2 & Mesitylene & 0.25 & 100 & $5 / 20$ & $43 / 86$ & 2.0 & 91 \\
\hline P3 & Toluene & 0.25 & 100 & $2 /-$ & $61 / 113$ & 1.9 & 85 \\
\hline P4 & Mesitylene & 0.1 & 100 & $2 /-$ & $103 / 516$ & 5.0 & 79 \\
\hline P5 & Mesitylene & 0.25 & 100 & $2 /-$ & 76/188 & 2.5 & 90 \\
\hline P6 & Mesitylene & 0.25 & 80 & $2 /-$ & $113 / 295$ & 2.6 & 90 \\
\hline P7 & Mesitylene & 0.5 & 100 & $2 /-$ & $64 / 140$ & 2.2 & 86 \\
\hline
\end{tabular}

${ }^{a} \mathrm{NDIBr}_{2}$ (1.0 eq.), $\mathrm{Ph}_{6}$-IDT (1.0 eq.), PivOH (1 eq.) and $\mathrm{K}_{2} \mathrm{CO}_{3}$ (3 eq.) were used in all entries. ${ }^{b}$ From size exclusion chromatography (SEC) in $\mathrm{CHCl}_{3} \cdot{ }^{c}$ Isolated yield after Soxhlet extraction with acetone, ethyl acetate and chloroform. 

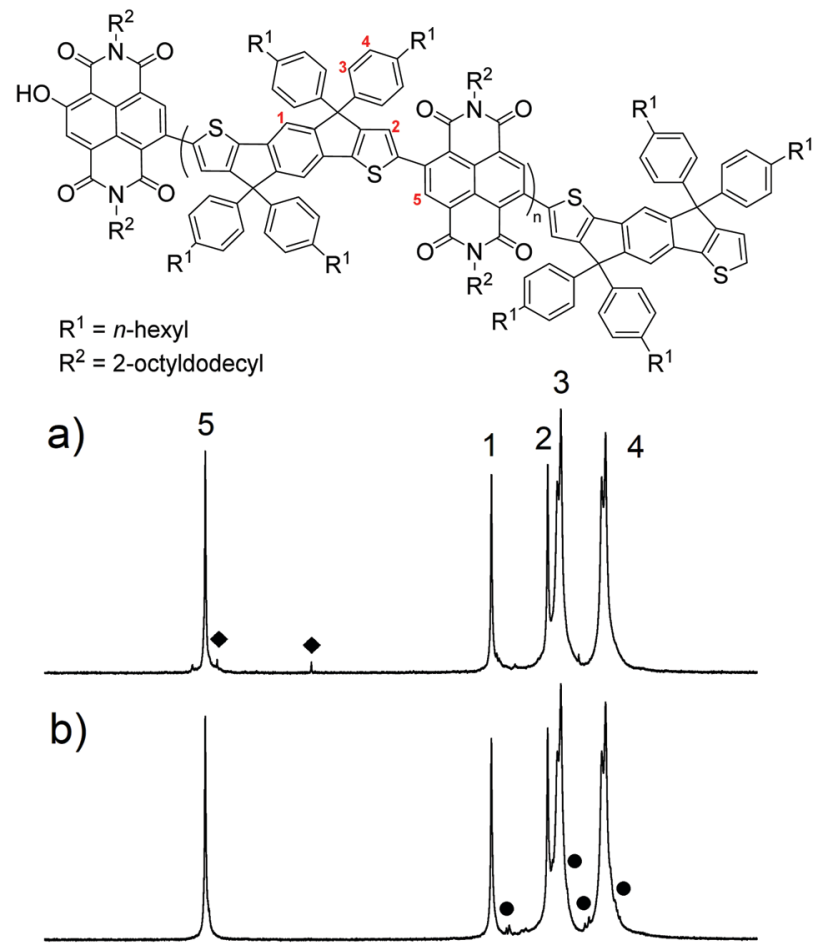

C)

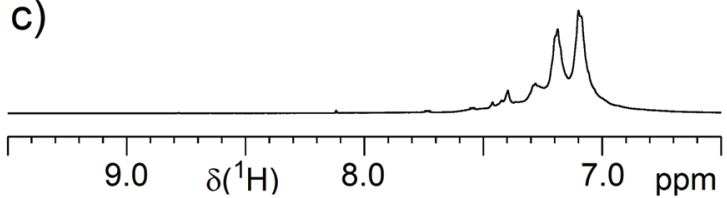

Fig. $1{ }^{1} \mathrm{H}$ NMR spectra of (a) P7 and (b) P6. (c) depicts the ${ }^{1} \mathrm{H}$ NMR spectrum of model compound $\mathrm{Ph}_{8}$-PIDT. Squares and dots mark signals of the $-\mathrm{NDI}-\mathrm{OH}$ and the $-\mathrm{IDT}-\mathrm{H}$ end groups, respectively.

higher catalyst loading in combination with the addition of a phosphine-ligand facilitates nucleophilic substitution of NDI$\mathrm{Br}$ chain ends by pivalate, leading to NDI-OH end groups (after hydrolysis) and accordingly low molar mass. ${ }^{18,26,53}$

High temperature ${ }^{1} \mathrm{H}$ NMR measurements at $120{ }^{\circ} \mathrm{C}$ in $\mathrm{C}_{2} \mathrm{D}_{2} \mathrm{Cl}_{4}$ allow to prove this end group by a characteristic signal $^{53}$ at $8.38 \mathrm{ppm}$ for the proton ortho to the $\mathrm{OH}$ group (Fig. 1a). Without the usage of the P-ligand the polymers contain predominantly - IDT-H end groups (Fig. 1b and Fig. S2, ESI $\dagger$ ). $\mathrm{Ph}_{8}$-PIDT is a model compound for IDT-IDT homocouplings. The signals from the phenyl rings do not overlap with P(NDI-IDT) signals and their appearance in the $\mathrm{P}(\mathrm{NDI}-\mathrm{IDT})$ spectrum should indicate such defects. Fortunately, the ${ }^{1} \mathrm{H}$ NMR signals of the $\mathrm{P}$ (NDI-IDT) backbone are well separated, but apart from end group signals, additional signals that indicate structural defects are absent. We therefore conclude that P(NDI-IDT) is defect-free, which is in accordance with similar NDI copolymers made by DAP. ${ }^{18,26,53,54}$ Detailed ${ }^{1} \mathrm{H}$ and ${ }^{13} \mathrm{C}$ NMR analyses are provided in the ESI $\dagger$ (Fig. S1-S4).

\section{Optoelectronic and thermal properties}

The UV-vis spectra of P(NDI-IDT) in dependence of molecular weight are shown in Fig. $2 a$ and $b$.
In chloroform solution, the polymers are characterized by a pronounced $\pi-\pi^{*}$ band at $395 \mathrm{~nm}$ and a broad charge transfer (CT) band at $728 \mathrm{~nm}$ with an absorption edge at $818 \mathrm{~nm}$ and a slight vibronic shoulder around $650 \mathrm{~nm}$. Neither molecular weight nor the nature of the end groups influence the shape of the absorption spectra. In contrast, the molar extinction coefficients are strongly dependent on molecular weight (Table 2). ${ }^{61}$ Compared to P(NDIT2), the absorption maximum of the low energy band exhibits a bathochromic shift of $35 \mathrm{~nm}$ (Fig. 2b), that can be attributed to the stronger donor strength of the IDT building block compared to bithiophene. However, the relative intensity of the CT band is lower, pointing to a reduced electronic interaction between NDI and IDT. ${ }^{23,26}$ To investigate the optical properties in more detail we chose polymer $\mathbf{P 3}$ with a medium molar mass of $\sim 60 \mathrm{~kg} \mathrm{~mol}^{-1}$ (Fig. $2 \mathrm{c}$ and d). The solvent has a moderate impact on absorbance. The vibronic shoulder of the CT band is most pronounced in the non-polar solvent toluene. In polar solvents such as tetrahydrofurane (THF) and dichloromethane (DCM) the CT band is slightly blueshifted (Fig. 2c). High-temperature UV-vis spectra do not show significantly altered spectra (Fig. S6, ESI $\dagger$ ). All these results are consistent with highly soluble copolymers that feature weak aggregation in solution. This is different to the optical behavior of P(NDIT2) and is caused by the additional side chains of P(NDI-IDT) located at IDT which hamper ordering processes. ${ }^{62}$

Thin film absorption and the influence of the annealing temperature is displayed in Fig. 2d. As spun films show spectra qualitatively similar to those of toluene solutions but with bathochromic shifts of around $40 \mathrm{~nm}$. The spectral shift and the increased intensity of the CT band is attributed to conformational changes/planarization of the polymer backbone as well as chainchain interactions during film formation. Thermal annealing below main chain melting ( $c f$. Fig. 4 ) at temperatures of $100-150{ }^{\circ} \mathrm{C}$ slightly changes CT band intensity. Annealing at $250{ }^{\circ} \mathrm{C}$, which is above $T_{\mathrm{m} 2}$, however, reduces CT band intensity as well as causes a hypsochromic shift of $16 \mathrm{~nm}$. Additionally, a new band with low intensity and of unknown nature around $850 \mathrm{~nm}$ appears. The onset of the absorption band is used to determine the optical bandgap of P1-P4. The spectra reveal an optical bandgap for P(NDI-IDT) of $1.57 \mathrm{eV}$ in solution and a slightly smaller band gap of $1.50 \mathrm{eV}$ in film. The electrical band gaps extracted from cyclic voltammetry (CV), are about $1.85 \mathrm{eV}$ in film and $1.69 \mathrm{eV}$ in solution, respectively (Fig. 3 and Table 3).

Compared to CV measurements in solution with a calculated HOMO of $-5.32 \mathrm{eV}$, the determination from film CV results in a lower lying HOMO energy level of $-5.56 \mathrm{eV}$ (Table 3 and Fig. 3). However, the reduction onset $E($ Red) in solution and film are similar yielding comparable LUMO energy levels of $-3.63 \mathrm{eV}$ and $-3.71 \mathrm{eV}$, respectively. The calculated LUMOs are slightly less negative than reported values for $\mathrm{P}(\mathrm{NDIT} 2)^{23,26,38}$ and reflect the stronger donor character of IDT in comparison to bithiophene.

P(NDI-IDT) shows excellent thermal stability with a degradation temperature greater than $440{ }^{\circ} \mathrm{C}$ (Fig. S7, ESI $\dagger$ ). The thermal properties were further investigated by differential 
a)

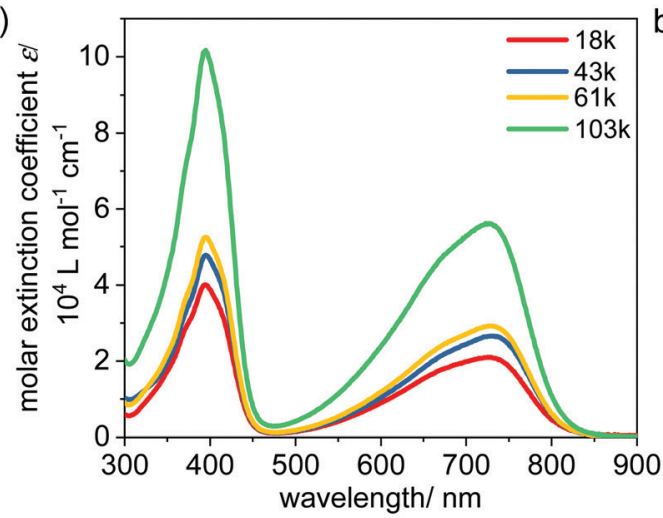

c)

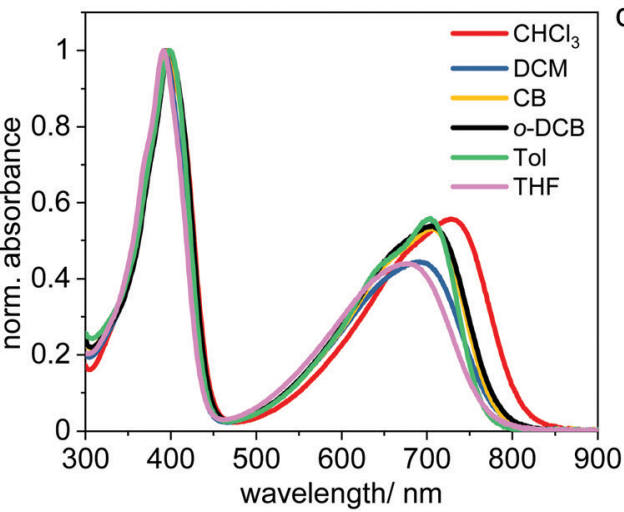

b)

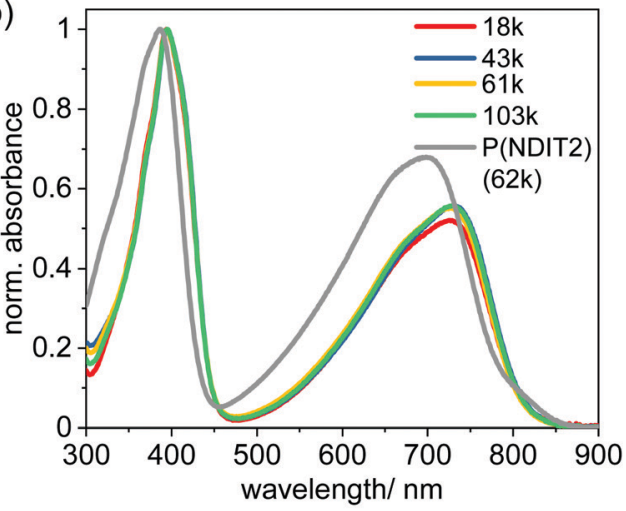

d)

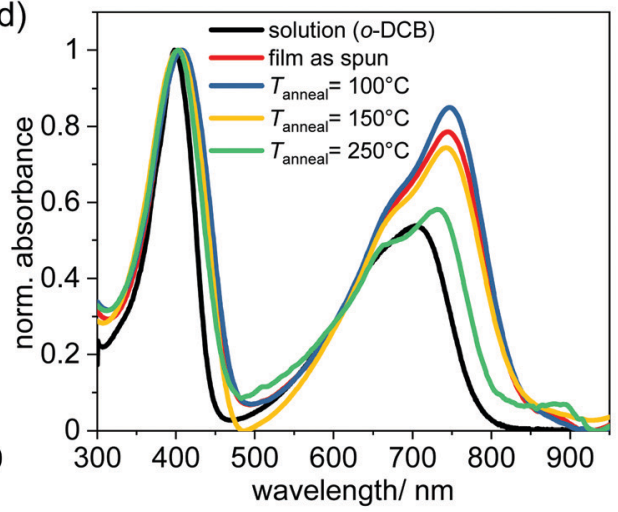

Fig. 2 Molar extinction coefficient (a) and normalized (b) UV-vis spectra of P(NDI-IDT) of different $M W\left(M_{n}\right.$ in $\left.\mathrm{g} \mathrm{mol}^{-1}\right)$ in chloroform solution at room temperature. Solvent dependent (c) and film (d) UV-vis spectra of P3 $\left(M_{n}=61 \mathrm{~kg} \mathrm{~mol}^{-1}\right)$.

Table 2 Summary of optical and thermal properties of selected samples

\begin{tabular}{llllllll}
\hline Entry & $\begin{array}{l}M_{\mathrm{n}} / M_{\mathrm{w}}{ }^{a} \\
\left(\mathrm{~kg} \mathrm{~mol}^{-1}\right)\end{array}$ & $\begin{array}{l}\lambda_{\text {abs,max }}{ }^{b} \\
(\mathrm{~nm})\end{array}$ & $\begin{array}{l}\varepsilon_{\mathrm{absmax}}{ }^{b} \\
\left(10^{3} \mathrm{~L} \mathrm{~mol}^{-1} \mathrm{~cm}^{-1}\right)\end{array}$ & $\begin{array}{l}T_{\mathrm{m} 1}{ }^{c} \\
\left({ }^{\circ} \mathrm{C}\right)\end{array}$ & $\begin{array}{l}T_{\mathrm{m} 2}{ }^{c} \\
\left({ }^{\circ} \mathrm{C}\right)\end{array}$ & $\begin{array}{l}T_{\mathrm{c}}{ }^{c} \\
\left({ }^{\circ} \mathrm{C}\right)\end{array}$ & $\begin{array}{l}\Delta H_{\mathrm{m} 2}{ }^{c} \\
\left(\mathrm{~J} \mathrm{~g}^{-1}\right)\end{array}$ \\
\hline P1 & $18 / 25$ & $394 / 726$ & 21 & 68 & 183 & 178 & 4.03 \\
P2 & $43 / 86$ & $395 / 731$ & 27 & 65 & 202 & 191 & 1.90 \\
P3 & $61 / 113$ & $395 / 728$ & 29 & 66 & 207 & 196 & 0.79 \\
P4 & $103 / 516$ & $394 / 726$ & 56 & 69 & 213 & 201 & 0.64 \\
\hline $\left.\mathrm{J} \mathrm{g}^{-1}\right)$
\end{tabular}

${ }^{a}$ From SEC in $\mathrm{CHCl}_{3} \cdot{ }^{b}$ Measured in chloroform at room temperature; molar extinction coefficient was calculated from maximum wavelength of the low-energy band (see non-italic values). ${ }^{c}$ DSC measured with $20 \mathrm{~K} \mathrm{~min}^{-1}$ under $\mathrm{N}_{2}$.

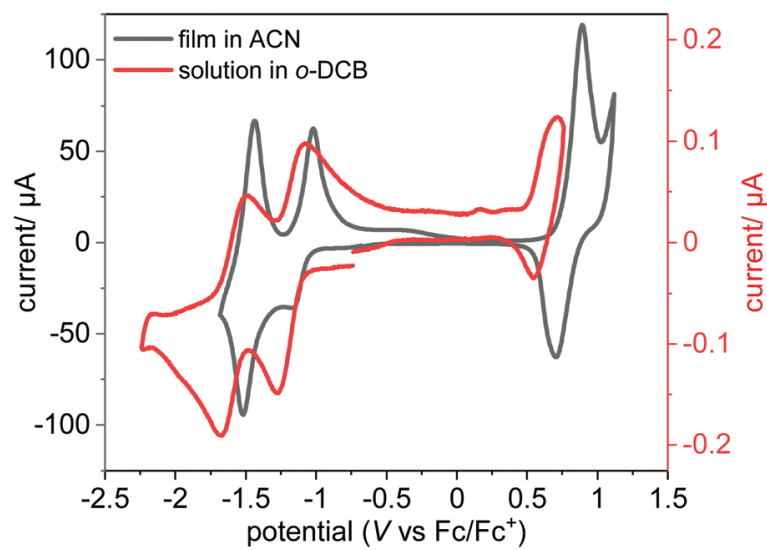

Fig. 3 Cyclic voltammograms of P(NDI-IDT) as film deposited on an ITO substrate in a $0.1 \mathrm{M} \mathrm{NBu}_{4} \mathrm{PF}_{6}$ acetonitrile solution (black) and in a $0.1 \mathrm{M}$ $\mathrm{NBu}_{4} \mathrm{PF}_{6} \mathrm{O}-\mathrm{DCB}$ solution (red) at a scan rate of $50 \mathrm{mV} \mathrm{s}^{-1}$.
Table 3 Summary of electrochemical properties

\begin{tabular}{|c|c|c|c|c|c|c|c|c|}
\hline & $\begin{array}{l}\lambda_{\mathrm{abs}}^{\text {onset }} \\
(\mathrm{nm})\end{array}$ & $\begin{array}{l}E_{\mathrm{g}, \mathrm{opt}}{ }^{c} \\
(\mathrm{eV})\end{array}$ & $\begin{array}{l}E_{\mathrm{g}, \mathrm{el}} \\
(\mathrm{eV})\end{array}$ & $\begin{array}{l}E_{\text {ox }} \\
\text { (V) }\end{array}$ & $\begin{array}{l}E_{\text {red }} \\
\text { (V) }\end{array}$ & $\begin{array}{l}E_{\mathrm{red}}{ }^{1 / 2} \\
(\mathrm{~V})\end{array}$ & $\begin{array}{l}\mathrm{HOMO}^{d} \\
(\mathrm{eV})\end{array}$ & $\begin{array}{l}\text { LUMO }^{d} \\
(\mathrm{eV})\end{array}$ \\
\hline Film $^{a}$ & 824 & 1.50 & 1.85 & 0.76 & -1.09 & -1.10 & -5.56 & -3.71 \\
\hline Solution $^{b}$ & 789 & 1.57 & 1.69 & 0.53 & -1.12 & -1.17 & -5.32 & -3.63 \\
\hline
\end{tabular}

scanning calorimetry (DSC) as a function of molecular weight (Table 2 and Fig. S8, ESI†). P1-P4 exhibit weakly semicrystalline behavior seen by two broad and weak endothermic transitions during heating around $T_{\mathrm{m} 1}=68{ }^{\circ} \mathrm{C}$ and $T_{\mathrm{m} 2}=178-223{ }^{\circ} \mathrm{C}$ depending on molecular weight. Both transitions are most distinct in P1 with lowest MW (Fig. 4a and Fig. S8, ESI $\dagger$ ). 

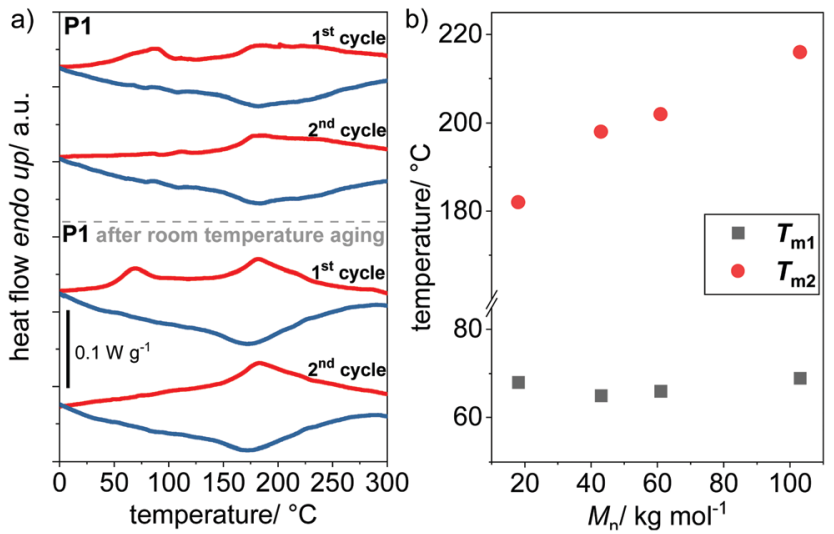

Fig. 4 (a) DSC curves of P1 $\left(M_{n}=18 \mathrm{~kg} \mathrm{~mol}^{-1}\right)$. First and second cycles were measured under $\mathrm{N}_{2}$ with $10 \mathrm{~K} \mathrm{~min}^{-1}$ before and with $20 \mathrm{~K} \mathrm{~min}^{-1}$ after room temperature aging; (b) side chain $T_{\mathrm{m} 1}$ and main chain $T_{\mathrm{m} 2}$ melting transitions in dependence of $M_{\mathrm{W}}$.

$T_{\mathrm{m} 1}$ around $68{ }^{\circ} \mathrm{C}$ vanishes in the second heating cycle and reappears in the first heating cycle after the sample was stored at room temperature for several weeks. In analogy to $\mathrm{P} 3 \mathrm{HT},{ }^{63}$ we hypothesize that $T_{\mathrm{m} 1}$ arises from side chain melting and $T_{\mathrm{m} 2}$ from main chain melting (Fig. 4b). Apparently the rather high density of side chains of P(NDI-IDT) allows for some ordering, and thus, for the appearance of an endothermic peak in the DSC traces not seen with P(NDIT2). The mixed structure of side chains and their rather random orientation may cause the slow crystallization over a time scale much larger than that of the DSC experiment.

\section{Charge transport properties}

Organic field-effect transistor (OFET) devices with a top-gate bottom-contact configuration were fabricated to investigate the electron transport properties of P(NDI-IDT). The devices show $\mathrm{n}$-channel behaviour and were optimized by screening the solvent for spin coating, annealing temperature, contact engineering and channel length (Fig. 5 and Fig. S9, S10, ESI $\dagger$ ). While the solvent seems to have a minor influence on the transfer characteristic curves, the annealing temperature has a greater impact (Fig. 5a and b). Annealing of the devices at moderate temperatures, up to $150{ }^{\circ} \mathrm{C}$, is necessary to enhance their performance, but is deleterious for annealing temperatures that approach $T_{\mathrm{m} 2}$ (Fig. $5 \mathrm{~b}$ and Table 4).

The charge mobilities of the optimized OFET devices in the saturation regime $\left(V_{\mathrm{d}}=40 \mathrm{~V}\right)$ are in the order of $10^{-3} \mathrm{~cm}^{2} \mathrm{~V}^{-1} \mathrm{~s}^{-1}$ (Table 5). The reduction of the channel length from 20 to $5 \mu \mathrm{m}$ resulted in a correct scaling of currents, suggesting that contact resistance is not a limiting factor for the estimated field-effect mobility. The current as well as electron mobility increases with increasing molecular weight up to $M_{\mathrm{n}}=61 \mathrm{~kg} \mathrm{~mol}^{-1}$ and afterwards slightly decreases for the highest MW sample P4 (Fig. 5c and d).
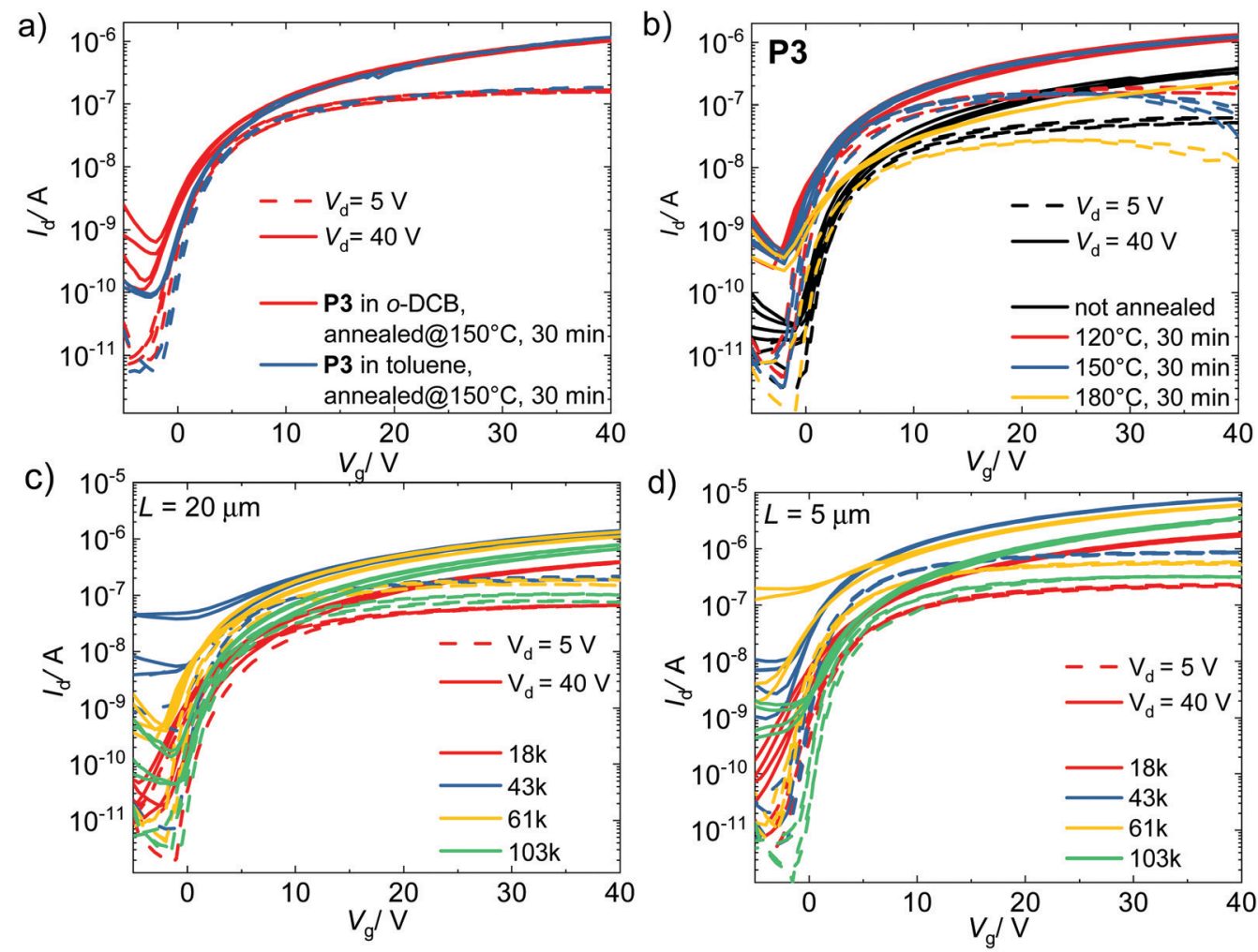

Fig. 5 Optimization of OFET devices. Effect of solvent for spin coating (a) and annealing temperature for P3 (b). Transfer curves of optimized devices as a function of $\mathrm{MW}\left(\mathrm{g} \mathrm{mol}^{-1}\right.$ ) and channel length (c and d). 
Table 4 OFET data of P3 devices at different annealing temperatures ${ }^{a}$

\begin{tabular}{llll}
\hline$T_{\text {anneal }}\left({ }^{\circ} \mathrm{C}\right)$ & $V_{\mathrm{th}}{ }^{b}(\mathrm{~V})$ & On/off ratio & $\mu_{\mathrm{sat}}{ }^{c}\left(\mathrm{~cm}^{2} \mathrm{~V}^{-1} \mathrm{~s}^{-1}\right)$ \\
\hline Not annealed & 2.8 & $\sim 10^{3}$ & $1.5 \times 10^{-3}$ \\
120 & 1.9 & $\sim 10^{4}$ & $3.9 \times 10^{-3}$ \\
150 & 1.7 & $\sim 10^{4}$ & $4.2 \times 10^{-3}$ \\
180 & 2.5 & $\sim 10^{3}$ & $5.3 \times 10^{-4}$ \\
$250^{d}$ & - & - & -
\end{tabular}

${ }^{a}$ Devices with $L=20 \mu \mathrm{m}$ were used in all entries. ${ }^{b}$ Calculated at $V_{\mathrm{d}}=5 \mathrm{~V}$ in linear scale. ${ }^{c}$ Calculated at $V_{\mathrm{d}}=40 \mathrm{~V} .{ }^{d}$ No mobilities could be extracted due to noise in the measurements.

Table 5 OFET characteristics of optimized devices $\left(T_{\text {anneal }}=150{ }^{\circ} \mathrm{C}\right)$ in dependence of $\mathrm{MW}^{\mathrm{a}}$

\begin{tabular}{lllll}
\hline Entry & $\begin{array}{l}M_{\mathrm{n}} / M_{\mathrm{w}} \\
\left(\mathrm{kg} \mathrm{mol}^{-1}\right)\end{array}$ & $\begin{array}{l}V_{\mathrm{th}}{ }^{b} \\
(\mathrm{~V})\end{array}$ & $\begin{array}{l}\text { On/off } \\
\text { ratio }^{c}\end{array}$ & $\begin{array}{l}\mu_{\text {sat }}{ }^{d} \\
\left(\mathrm{~cm}^{2} \mathrm{~V}^{-1} \mathrm{~s}^{-1}\right)\end{array}$ \\
\hline P1 & $18 / 25$ & 1.8 & $\sim 10^{3}$ & $1.1 \times 10^{-3}$ \\
P2 & $43 / 86$ & 2.8 & $\sim 10^{2}$ & $4.4 \times 10^{-3}$ \\
P3 & $61 / 113$ & 1.9 & $\sim 10^{3}$ & $3.9 \times 10^{-3}$ \\
P4 & $103 / 516$ & 3.4 & $\sim 10^{4}$ & $1.7 \times 10^{-3}$
\end{tabular}

${ }^{a}$ Devices with $L=20 \mu \mathrm{m}$ were used in all entries. ${ }^{b}$ Calculated at $V_{\mathrm{d}}=5 \mathrm{~V}$ in linear scale. ${ }^{c}$ Values are similar for $V_{\mathrm{d}}=5 \mathrm{~V}$ and $V_{\mathrm{d}}=40 \mathrm{~V}$. ${ }^{d}$ Calculated at $V_{\mathrm{d}}=40 \mathrm{~V}$.

Overall, the MW dependence of mobility is rather limited. In general, electron mobilities are up to three orders of magnitude lower than the reported values for P(NDIT2). ${ }^{26}$

In order to better understand the OFET behaviour as a function of the annealing temperature, we first carried out photothermal deflection spectroscopy (PDS) on thin films of P3 and $\mathrm{P}$ (NDIT2) as reference. This sensitive technique provides insight into the electronic order of polymer thin films. Thereby, the bandgap edge absorption of polymer films is measured to extract the so-called Urbach energy $U_{\mathrm{E}} . U_{\mathrm{E}}$ is known to be related to the degree of energetic disorder of the material and hence is typically associated with the charge transport properties. ${ }^{41,42,64,65}$ The thin films were prepared analogously to the OFET fabrication process. P(NDI-IDT) P3 exhibits a sharp sub-band gap absorption and an extracted value $U_{\mathrm{E}}=(29.3 \pm 0.9) \mathrm{meV}\left(T_{\text {anneal }}=120^{\circ} \mathrm{C}\right)$. The value is comparable to P(NDIT2) which exhibits $U_{\mathrm{E}}=(30.6 \pm 0.9) \mathrm{meV}$ (Fig. 6 and Table 6). Further experiments in which the influence of annealing temperature on the energetic disorder were investigated, show that annealing at temperature higher than $150{ }^{\circ} \mathrm{C}$ is detrimental for the energetic order of the material (Table 6). Interestingly, the lowest Urbach energy $(28.2 \pm 1.0 \mathrm{meV})$ could be extracted from the absorption of the $\mathbf{P} \mathbf{3}$ as spun thin film, which is one of the lowest reported values for conjugated polymers (Fig. 6). ${ }^{42,66}$ These observations clearly show that $U_{\mathrm{E}}$ alone cannot grasp the complexity of charge transport process in a polymer thin film. While $U_{\mathrm{E}}$ can help to understand the relation between thin film morphology and energetic order of optically probed states, the accessibility of such states along the channel of a transistors through an efficient percolative path is a requirement for high carrier mobility. The presence of bulky hexylphenyl side chains at the IDT unit, hindering solution aggregation, as well as crystallization and overall

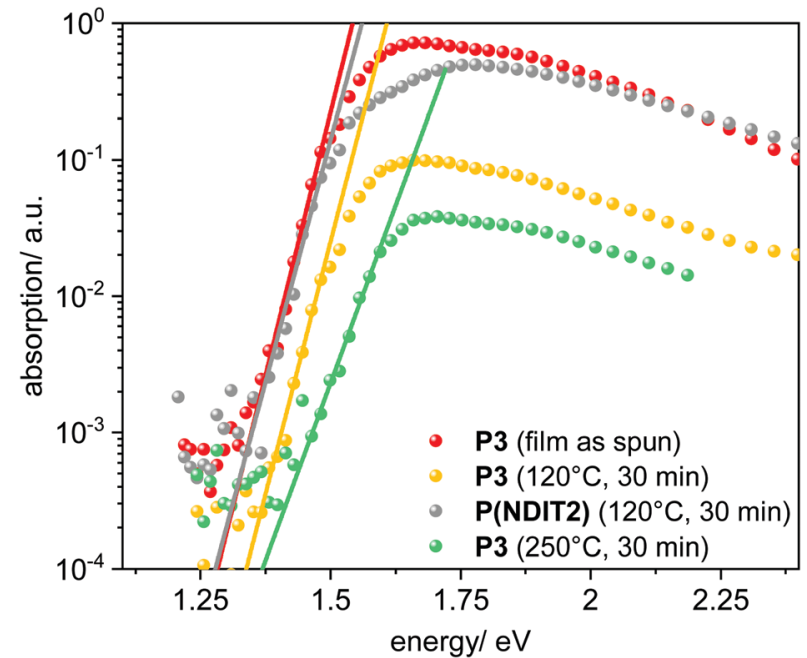

Fig. 6 Comparison between the absorption of P3 $\left(M_{n}=61 \mathrm{~kg} \mathrm{~mol}^{-1}\right)$ and P(NDIT2) $\left(M_{n}=62 \mathrm{~kg} \mathrm{~mol}^{-1}\right)$ thin films in dependence of the annealing temperature; measured by photothermal deflection spectroscopy. The solid line displays the corresponding exponential fits for extraction of the Urbach energy $U_{\mathrm{E}}$. Films were spin-coated (1000 rpm, $60 \mathrm{~s}$ ) from o-DCB solutions.

Table 6 Urbach energy of P3 and P(NDIT2) in dependence of annealing temperature $^{a}$

\begin{tabular}{lll}
\hline Entry & $T_{\text {anneal }}{ }^{a}\left({ }^{\circ} \mathrm{C}\right)$ & $U_{\mathrm{E}}(\mathrm{meV})$ \\
\hline P3 & Not annealed & $28.2 \pm 1.0$ \\
P3 & 120 & $29.3 \pm 0.9$ \\
P3 & 250 & $41.7 \pm 2.9$ \\
P(NDIT2) & 120 & $30.6 \pm 2.0$
\end{tabular}

${ }^{a}$ Films were spin-coated $(1000 \mathrm{rpm}, 60 \mathrm{~s})$ from $o$-DCB solutions and annealed at the given temperature for 30 min under argon.

interconnectivity in thin films, can have a drastic effect on morphology and interchain transport. The latter plays a dominant role in the case of highly localized states, as is typical of NDI-based co-polymers, where intrachain transport is not effective. ${ }^{67,68}$

\section{GIWAXS measurements}

To gain further information about the molecular packing of $\mathrm{P}$ (NDI-IDT), grazing incidence wide-angle X-ray scattering (GIWAXS) measurements were performed on thin films of $\mathbf{P 3}$. The films were prepared using the conditions for the best OFET device with $T_{\text {anneal }}=120{ }^{\circ} \mathrm{C}$ (below main chain melting) and, in comparison, for annealing above main chain melting at $T_{\text {anneal }}=250{ }^{\circ} \mathrm{C}$. The results are illustrated in Fig. $7 \mathrm{a}-\mathrm{d}$. The sample annealed at $120^{\circ} \mathrm{C}$ shows a low degree order suggesting a liquid crystalline organization rather than a crystalline one. The observed (100) and (200) peaks at $q=0.334 \AA^{-1}$ and $q=0.668 \AA^{-1}$ allowed determining the interchain $d_{100^{-}}$-spacing along the side chain direction being $18.81 \AA$. The azimuthal distribution of the (100) peak clearly indicates a preferential edge-on orientation (Fig. 7a and b). Furthermore, the 2D GIWAXS image and the 1D scattering curves extracted from it 
a)

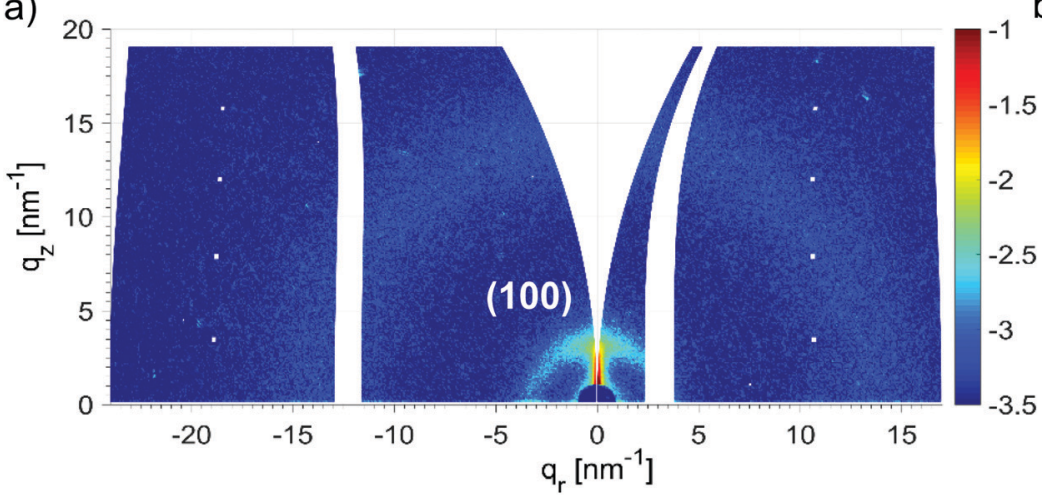

c)

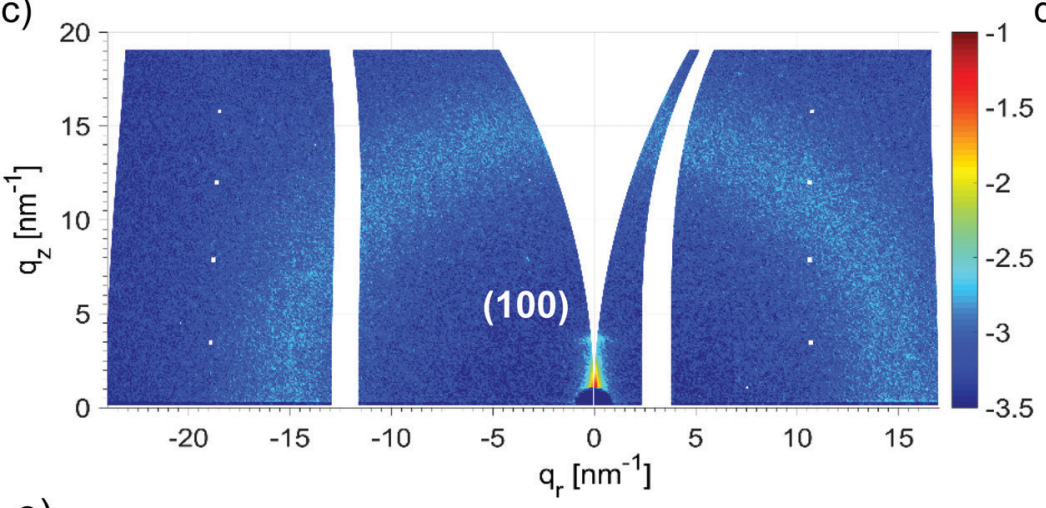

e)

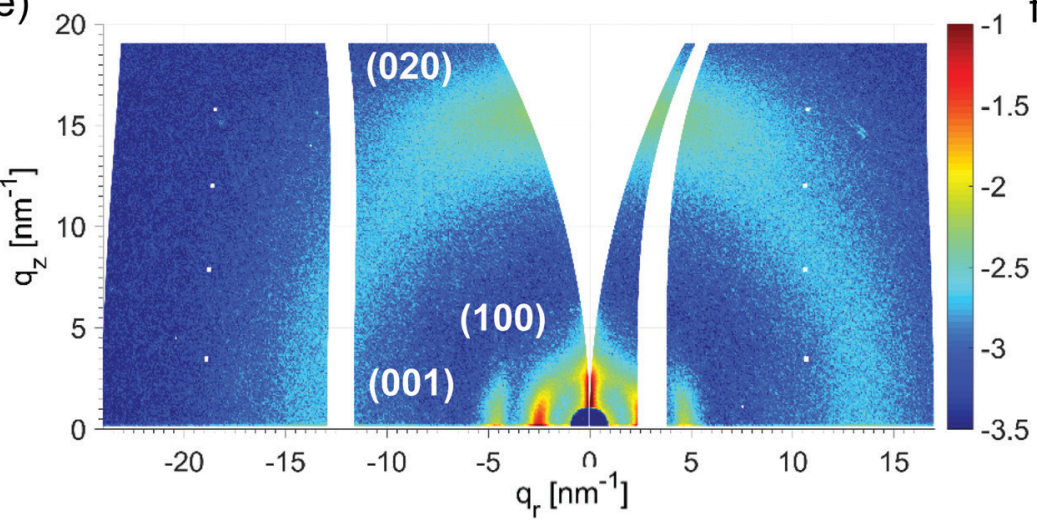

b)

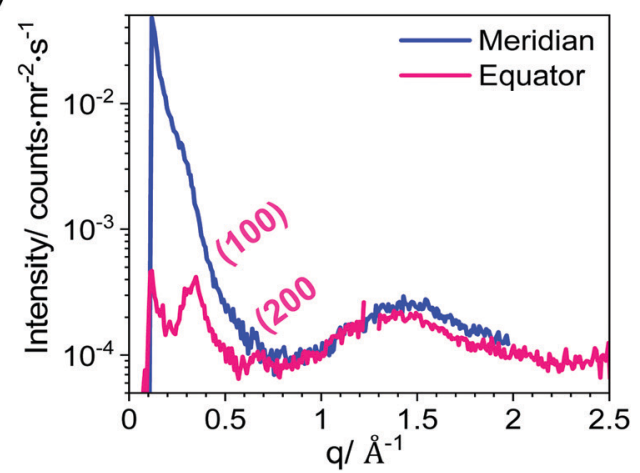

d)

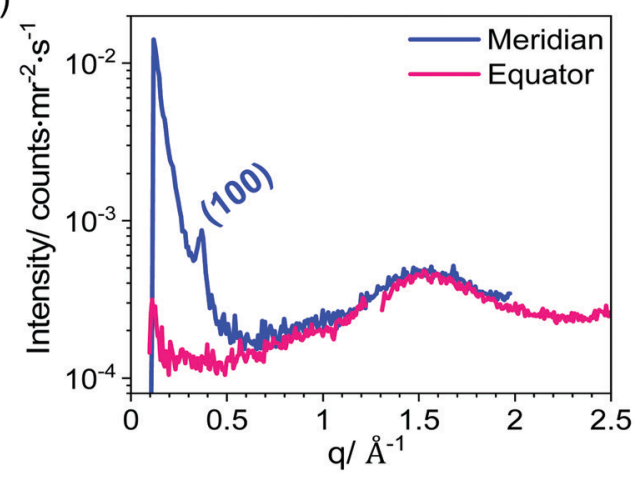

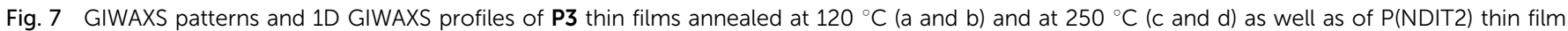
annealed at $120{ }^{\circ} \mathrm{C}$ (e and f).

along meridian and equator do not show any prominent $\pi-\pi$ stacking peaks (Fig. 7a and b). Such observation confirms the drastic effect of the molecular structure on the $\pi-\pi$ stacking disorder, introducing energetic barriers to interchain transport of electrons through the films. Upon annealing at $250{ }^{\circ} \mathrm{C}$ (Fig. $7 \mathrm{c}$ and d) the material evidences a solely edge-on orientation and a significantly reduced molecular ordering, as the area below the (100) peak decreased by about 20 times (see ESI, $\dagger$ Figure S11), with a slightly decreased $d_{100}$-spacing. The dependence of the annealing temperature on the molecular ordering complies with the previously discussed reduction of the CT absorption band and can partly explain the diminished mobilities for annealing above $150{ }^{\circ} \mathrm{C}$.

In order to investigate the difference of ordering between $\mathrm{P}$ (NDI-IDT) and P(NDIT2), the GIWAXS measurements of a
$\mathrm{P}$ (NDIT2) film annealed at $120{ }^{\circ} \mathrm{C}$ were carried out (Fig. 7e and $\mathrm{f}$ ). In contrast to the edge-on orientation of P(NDI-IDT), $\mathrm{P}(\mathrm{NDIT} 2)$ exhibits a predominant face-on orientation. In addition, a (020) diffraction peak corresponding to the $\pi-\pi$ stacking distance of $3.94 \AA$ can be monitored suggesting a significantly higher crystalline order than that in P(NDI-IDT).

\section{Experimental}

\section{Materials and methods}

All starting materials were purchased from commercial sources and used without further purification unless otherwise specified. All reactions were carried out in flame dried glassware and under dry inert gas atmosphere. Compounds $\mathrm{Ph}_{6} \mathrm{IDT}, \mathrm{NDIBr}_{2}$ 
and the model compound $\mathrm{Ph}_{8}$-PIDT were synthesized according to published protocols. ${ }^{59,60,69}$

Detailed information about instrumentation and experimental procedures are described in the ESI. $\dagger$ SEC curves of the samples P1-P7 are shown in Fig. S5.

\section{Synthetic procedures}

General synthetic procedure for synthesis of P(NDI-IDT) via DAP (P6). Ph $\mathrm{Ph}_{6} \mathrm{IDT}\left(141.1 \mathrm{mg}, 155.5 \mu \mathrm{mol}, 1\right.$ eq.), $\mathrm{NDIBr}_{2}$ (153.2 mg, $155.5 \mu \mathrm{mol}, 1$ eq.), pivalic acid $(15.9 \mathrm{mg}, 155.5 \mu \mathrm{mol}$, 1 eq.) and potassium carbonate $(64.5 \mathrm{mg}, 466.6 \mu \mathrm{mol}, 3 \mathrm{eq}$.) were placed in a vial and dissolved in $0.62 \mathrm{~mL}$ degassed mesitylene. Then $\mathrm{Pd}_{2} \mathrm{dba}_{3}(2.8 \mathrm{mg}, 2 \mathrm{~mol} \%)$ were added under argon and stirred for $48 \mathrm{~h}$ at $80{ }^{\circ} \mathrm{C}$. After cooling to room temperature, the mixture was diluted with chloroform, precipitated into methanol and purified by Soxhlet extraction with acetone, ethyl acetate and chloroform. The chloroform fraction was filtered through a silica gel plug and dried overnight in a vacuum oven at $50{ }^{\circ} \mathrm{C}$ to afford a dark green solid. Yield: $243 \mathrm{mg}(90 \%)$.

\section{Conclusions}

We have presented a robust and atom-economic friendly protocol to prepare highly soluble alternating copolymers made from naphthalene diimide (NDI) and indacenodithiophene (IDT) via direct arylation polycondensation. Detailed molecular characterizations indicate that $\mathrm{P}$ (NDI-IDT) is defect-free. Molecular weights (MWs) up to $M_{\mathrm{n}, \mathrm{SEC}}=113 \mathrm{~kg} \mathrm{~mol}^{-1}$ can be tuned by an appropriate adjustment of reaction conditions. The optical behaviour of the polymers indicate weakly aggregated chains. In solution, the absorption spectra are almost independent of temperature and moderately influenced by the type of solvent. Thermal annealing of thin films above $150{ }^{\circ} \mathrm{C}$ results in hypsochromically shifted spectra and reduced intensity of the CT band. While molar extinction coefficients and thermal properties do depend on MW, absorption onset and maximum of the charge transfer band are not affected by MW. DSC shows two weak and broad endothermic transitions which are ascribed to side chain and main chain melting. Optimization of the OFET devices reveal that annealing is important to boost performance, but it is deleterious at temperatures above $150{ }^{\circ} \mathrm{C}$, where films lose their weak crystallinity. Electron mobilities are moderate and mostly independent of MW for as spun films and entirely vanish for thermal annealing above main chain melting. Urbach energies are very low for as spun films but rather higher after thermal annealing above main chain melting. GIWAXS reveals a very weakly crystalline morphology of films after spin coating and an almost entirely amorphous morphology after thermal annealing above main chain melting. Taken together, both low Urbach energies as well as a semicrystalline morphology with chain-chain contacts are required for efficient charge transport. The latter is not possible in P(NDI-IDT) films, as the additional and bulky hexylphenyl side chains do not allow for significant solution aggregation and crystallization in thin films. These results emphasize the importance of interchain transport for high carrier mobility, especially if intrachain transport alone is not efficient as is the case with $\mathrm{P}$ (NDIT2). Side chain variation at the IDT monomer may allow control over aggregation for P(NDI-IDT) to capitalize on its very low Urbach energies as well as on fibrillar morphologies commonly seen with P(NDIT2).

\section{Author contributions}

D. Adamczak synthesized the polymers and characterized them by SEC, UV-vis and PL spectroscopy, cyclic voltammetry, TGA as well as DSC analyses. D. Adamczak wrote the first draft of the manuscript. B. Passarella and M. Caironi characterized the polymers in organic field-effect transistors. H. Komber performed high-temperature NMR spectroscopy and evaluated the data. D. Becker-Koch and Y. Vaynzof performed PDS experiments. O. Dolynchuk carried out the GIWAXS measurements and evaluated the data. S. Schmidt synthesized P(NDIT2). M. Sommer designed and supervised the work. All authors were involved in revising the manuscript.

\section{Conflicts of interest}

There are no conflicts to declare.

\section{Acknowledgements}

The authors thank M. Raisch and R. Hertel for DSC measurements and D. Stegerer for TGA measurements. M. S. acknowledges the DFG for funding (project SO1213/8-2). O. D. acknowledges financial support from the European Union (EFRE). Y. V. thanks the Fulbright Commission for support (Fulbright-Cottrell Award 2018). The OFETs fabrication of this work was partially carried out at Polifab, the micro- and nanotechnology center of the Politecnico di Milano.

\section{Notes and references}

1 Y. J. Wang and G. Yu, J. Polym. Sci., Part B: Polym. Phys., 2019, 57, 1557-1558.

2 J. de Mello, J. Anthony and S. Lee, ChemPhysChem, 2015, 16, 1099-1100.

3 R. M. Pankow and B. C. Thompson, Polymer, 2020, 207, 122874.

4 A. Facchetti, Chem. Mater., 2011, 23, 733-758.

5 S. Holliday, Y. Li and C. K. Luscombe, Prog. Polym. Sci., 2017, 70, 34-51.

6 M. Kim, S. U. Ryu, S. A. Park, K. Choi, T. Kim, D. Chung and T. Park, Adv. Funct. Mater., 2019, 1904545.

7 S. E. Root, S. Savagatrup, A. D. Printz, D. Rodriquez and D. J. Lipomi, Chem. Rev., 2017, 117, 6467-6499.

8 Y. Huang, D. L. Elder, A. L. Kwiram, S. A. Jenekhe, A. K. Y. Jen, L. R. Dalton and C. K. Luscombe, Adv. Mater., 2019, 1904239.

9 M. Goel, C. D. Heinrich, G. Krauss and M. Thelakkat, Macromol. Rapid Commun., 2019, 40, 1800915. 
10 Z. Genene, W. Mammo, E. Wang and M. R. Andersson, Adv. Mater., 2019, 31, 1807275.

11 A. F. Paterson, S. Singh, K. J. Fallon, T. Hodsden, Y. Han, B. C. Schroeder, H. Bronstein, M. Heeney, I. McCulloch and T. D. Anthopoulos, Adv. Mater., 2018, 30, 1801079.

12 H. Sun, X. Guo and A. Facchetti, Chem, 2020, 6, 1310-1326.

13 K.-J. Baeg, M. Caironi and Y.-Y. Noh, Adv. Mater., 2013, 25, 4210-4244.

14 T. L. D. Tam and J. Xu, J. Mater. Chem. A, 2021, 9, 5149-5163.

15 N. Zhou and A. Facchetti, Mater. Today, 2018, 21, 377-390.

16 M. Sommer, J. Mater. Chem. C, 2014, 2, 3088-3098.

17 X. Guo, A. Facchetti and T. J. Marks, Chem. Rev., 2014, 114, 8943-9021.

18 R. Matsidik, A. Luzio, S. Hameury, H. Komber, C. R. McNeill, M. Caironi and M. Sommer, J. Mater. Chem. C, 2016, 4, 10371-10380.

19 H. Yan, Z. Chen, Y. Zheng, C. Newman, J. R. Quinn, F. Dötz, M. Kastler and A. Facchetti, Nature, 2009, 457, 679-686.

20 B. Fan, L. Ying, P. Zhu, F. Pan, F. Liu, J. Chen, F. Huang and Y. Cao, Adv. Mater., 2017, 29, 1703906.

21 K. D. Deshmukh, R. Matsidik, S. K. K. Prasad, N. Chandrasekaran, A. Welford, L. A. Connal, A. C. Y. Liu, E. Gann, L. Thomsen, D. Kabra, J. M. Hodgkiss, M. Sommer and C. R. McNeill, ACS Appl. Mater. Interfaces, 2018, 10, 955-969.

22 N. Zhou, A. S. Dudnik, T. I. N. G. Li, E. F. Manley, T. J. Aldrich, P. Guo, H.-C. Liao, Z. Chen, L. X. Chen, R. P. H. Chang, A. Facchetti, M. Olvera de la Cruz and T. J. Marks, J. Am. Chem. Soc., 2016, 138, 1240-1251.

23 Y. Shin, A. Welford, H. Komber, R. Matsidik, T. ThurnAlbrecht, C. R. McNeill and M. Sommer, Macromolecules, 2018, 51, 984-991.

24 E. Zhou, M. Nakano, S. Izawa, J. Cong, I. Osaka, K. Takimiya and K. Tajima, ACS Macro Lett., 2014, 3, 872-875.

25 S. B. Schmidt, M. Hönig, Y. Shin, M. Cassinelli, A. Perinot, M. Caironi, X. Jiao, C. R. McNeill, D. Fazzi, T. Biskup and M. Sommer, ACS Appl. Polym. Mater., 2020, 2, 1954-1963.

26 R. Matsidik, M. Giorgio, A. Luzio, M. Caironi, H. Komber and M. Sommer, Eur. J. Org. Chem., 2018, 6121-6126.

27 J. W. Jung, J. W. Jo, C.-C. Chueh, F. Liu, W. H. Jo, T. P. Russell and A. K.-Y. Jen, Adv. Mater., 2015, 27, 3310-3317.

28 B. Zhu, L. Guo, P. Deng and S. Liu, J. Mater. Chem. C, 2021, 9, 2198-2204.

29 D. Kiefer, A. Giovannitti, H. Sun, T. Biskup, A. Hofmann, M. Koopmans, C. Cendra, S. Weber, L. J. Anton Koster, E. Olsson, J. Rivnay, S. Fabiano, I. McCulloch and C. Müller, ACS Energy Lett., 2018, 3, 278-285.

30 Y. Shin, H. Komber, D. Caiola, M. Cassinelli, H. Sun, D. Stegerer, M. Schreiter, K. Horatz, F. Lissel, X. Jiao, C. R. McNeill, S. Cimò, C. Bertarelli, S. Fabiano, M. Caironi and M. Sommer, Macromolecules, 2020, 53, 5158-5168.

31 H. You, D. Kim, H.-H. Cho, C. Lee, S. Chong, N. Y. Ahn, M. Seo, J. Kim, F. S. Kim and B. J. Kim, Adv. Funct. Mater., 2018, 28, 1803613.

32 A. Wadsworth, M. Moser, A. Marks, M. S. Little, N. Gasparini, C. J. Brabec, D. Baran and I. McCulloch, Chem. Soc. Rev., 2019, 48, 1596-1625.
33 K. Feng, J. Huang, X. Zhang, Z. Wu, S. Shi, L. Thomsen, Y. Tian, H. Y. Woo, C. R. McNeill and X. Guo, Adv. Mater., 2020, 32, 2001476.

34 H. Jia and T. Lei, J. Mater. Chem. C, 2019, 7, 12809-12821.

35 Y. Lu, J.-Y. Wang and J. Pei, Chem. Mater., 2019, 31, 6412-6423.

36 L. Xue, Y. Yang, Z.-G. Zhang, X. Dong, L. Gao, H. Bin, J. Zhang, Y. Yang and Y. Li, J. Mater. Chem. A, 2016, 4, 5810-5816.

37 S. Lee, C. Lee, H. Kim and Y. Kim, J. Mater. Chem. C, 2020, 8, 15778-15787.

38 S. Shi, P. Chen, Y. Chen, K. Feng, B. Liu, J. Chen, Q. Liao, B. Tu, J. Luo, M. Su, H. Guo, M. Kim, A. Facchetti and X. Guo, Adv. Mater., 2019, 31, 1905161.

39 Y. Li, M. Gu, Z. Pan, B. Zhang, X. Yang, J. Gu and Y. Chen, J. Mater. Chem. A, 2017, 5, 10798-10814.

40 C. Liang and H. Wang, Org. Electron., 2017, 50, 443-457.

41 A. Wadsworth, H. Chen, K. J. Thorley, C. Cendra, M. Nikolka, H. Bristow, M. Moser, A. Salleo, T. D. Anthopoulos, H. Sirringhaus and I. McCulloch, J. Am. Chem. Soc., 2020, 142, 652-664.

42 D. Venkateshvaran, M. Nikolka, A. Sadhanala, V. Lemaur, M. Zelazny, M. Kepa, M. Hurhangee, A. J. Kronemeijer, V. Pecunia, I. Nasrallah, I. Romanov, K. Broch, I. McCulloch, D. Emin, Y. Olivier, J. Cornil, D. Beljonne and H. Sirringhaus, Nature, 2014, 515, 384-388.

43 I. McCulloch, R. S. Ashraf, L. Biniek, H. Bronstein, C. Combe, J. E. Donaghey, D. I. James, C. B. Nielsen, B. C. Schroeder and W. Zhang, Acc. Chem. Res., 2012, 45, 714-722.

44 X. Zhang, H. Bronstein, A. J. Kronemeijer, J. Smith, Y. Kim, R. J. Kline, L. J. Richter, T. D. Anthopoulos, H. Sirringhaus, K. Song, M. Heeney, W. Zhang, I. McCulloch and D. M. DeLongchamp, Nat. Commun., 2013, 4, 2238.

45 C. Cordovilla, C. Bartolomé, J. M. Martínez-Ilarduya and P. Espinet, ACS Catal., 2015, 5, 3040-3053.

46 L. A. Estrada, J. J. Deininger, G. D. Kamenov and J. R. Reynolds, ACS Macro Lett., 2013, 2, 869-873.

47 N. S. Gobalasingham and B. C. Thompson, Prog. Polym. Sci., 2018, 83, 135-201.

48 N. Snoeij, Toxicol. Appl. Pharmacol., 1985, 81, 274-286.

49 D. J. Burke and D. J. Lipomi, Energy Environ. Sci., 2013, 6, 2053.

50 T. M. Pappenfus, F. Almyahi, N. A. Cooling, E. W. Culver, S. C. Rasmussen and P. C. Dastoor, Macromol. Chem. Phys., 2018, 219, 1800272.

51 S.-L. Suraru, J. A. Lee and C. K. Luscombe, ACS Macro Lett., 2016, 5, 724-729.

52 J.-R. Pouliot, F. Grenier, J. T. Blaskovits, S. Beaupré and M. Leclerc, Chem. Rev., 2016, 116, 14225-14274.

53 R. Matsidik, H. Komber, A. Luzio, M. Caironi and M. Sommer, J. Am. Chem. Soc., 2015, 137, 6705-6711.

54 R. Matsidik, H. Komber and M. Sommer, ACS Macro Lett., 2015, 4, 1346-1350.

55 Y. Shin, M. Massetti, H. Komber, T. Biskup, D. Nava, G. Lanzani, M. Caironi and M. Sommer, Adv. Electron. Mater., 2018, 4, 1700581.

56 S. Chen, K. C. Lee, Z.-G. Zhang, D. S. Kim, Y. Li and C. Yang, Macromolecules, 2016, 49, 527-536. 
57 Y. Li, W. K. Tatum, J. W. Onorato, S. D. Barajas, Y. Y. Yang and C. K. Luscombe, Polym. Chem., 2017, 8, 5185-5193.

58 Y. Li, W. K. Tatum, J. W. Onorato, Y. Zhang and C. K. Luscombe, Macromolecules, 2018, 51, 6352-6358.

59 D. Adamczak, H. Komber, A. Illy, A. D. Scaccabarozzi, M. Caironi and M. Sommer, Macromolecules, 2019, 52, 7251-7259.

60 D. Adamczak, A. Perinot, H. Komber, A. Illy, S. Hultmark, B. Passarella, W. L. Tan, S. Hutsch, D. Becker-Koch, C. Rapley, A. D. Scaccabarozzi, M. Heeney, Y. Vaynzof, F. Ortmann, C. R. McNeill, C. Müller, M. Caironi and M. Sommer, J. Mater. Chem. C, 2021, 9, 4597-4606.

61 M. S. Vezie, S. Few, I. Meager, G. Pieridou, B. Dörling, R. S. Ashraf, A. R. Goñi, H. Bronstein, I. McCulloch, S. C. Hayes, M. Campoy-Quiles and J. Nelson, Nat. Mater., 2016, 15, 746-753.

62 R. Steyrleuthner, M. Schubert, I. Howard, B. Klaumünzer, K. Schilling, Z. Chen, P. Saalfrank, F. Laquai, A. Facchetti and D. Neher, J. Am. Chem. Soc., 2012, 134, 18303-18317.

63 Z. Wu, A. Petzold, T. Henze, T. Thurn-Albrecht, R. H. Lohwasser, M. Sommer and M. Thelakkat, Macromolecules, 2010, 43, 4646-4653.
64 A. J. Kronemeijer, V. Pecunia, D. Venkateshvaran, M. Nikolka, A. Sadhanala, J. Moriarty, M. Szumilo and H. Sirringhaus, Adv. Mater., 2014, 26, 728-733.

65 H. Chen, A. Wadsworth, C. Ma, A. Nanni, W. Zhang, M. Nikolka, A. M. T. Luci, L. M. A. Perdigão, K. J. Thorley, C. Cendra, B. Larson, G. Rumbles, T. D. Anthopoulos, A. Salleo, G. Costantini, H. Sirringhaus and I. McCulloch, J. Am. Chem. Soc., 2019, 141, 18806-18813.

66 T. H. Thomas, D. J. Harkin, A. J. Gillett, V. Lemaur, M. Nikolka, A. Sadhanala, J. M. Richter, J. Armitage, H. Chen, I. McCulloch, S. M. Menke, Y. Olivier, D. Beljonne and H. Sirringhaus, Nat. Commun., 2019, 10, 2614.

67 R. Noriega, J. Rivnay, K. Vandewal, F. P. V. Koch, N. Stingelin, P. Smith, M. F. Toney and A. Salleo, Nat. Mater., 2013, 12, 1038-1044.

68 A. Onwubiko, W. Yue, C. Jellett, M. Xiao, H.-Y. Chen, M. K. Ravva, D. A. Hanifi, A.-C. Knall, B. Purushothaman, M. Nikolka, J.-C. Flores, A. Salleo, J.-L. Bredas, H. Sirringhaus, P. Hayoz and I. McCulloch, Nat. Commun., 2018, 9, 416.

69 X. Guo and M. D. Watson, Org. Lett., 2008, 10, 5333-5336. 